This item was submitted to Loughborough's Research Repository by the author.

Items in Figshare are protected by copyright, with all rights reserved, unless otherwise indicated.

\title{
Scaling the cricket pitch to fit junior players
}

PLEASE CITE THE PUBLISHED VERSION

https://doi.org/10.1080/02640414.2020.1804518

PUBLISHER

Taylor \& Francis

VERSION

AM (Accepted Manuscript)

PUBLISHER STATEMENT

This is an Accepted Manuscript of an article published by Taylor \& Francis in Journal of Sports Sciences on 14 August 2020, available online: http://www.tandfonline.com/10.1080/02640414.2020.1804518.

\section{LICENCE}

CC BY-NC-ND 4.0

\section{REPOSITORY RECORD}

Harwood, Mike, Fred Yeadon, and Mark King. 2020. "Scaling the Cricket Pitch to Fit Junior Players". Loughborough University. https://hdl.handle.net/2134/12923477.v1. 


\title{
Scaling the cricket pitch to fit junior players
}

\author{
${ }^{1}$ Michael J. Harwood, Maurice R. Yeadon and Mark A King \\ ${ }^{1}$ School of Sport, Exercise and Health Sciences, Loughborough University, Leicestershire, LE11 3TU, UK
}

\begin{abstract}
Studies in several sports have shown the benefits of adapting the playing environment to fit junior players. Frequently the changes are pragmatic choices based on space constraints or existing line markings, or the result of simple scaling based on stature. In this study, a method of scaling the cricket pitch length is presented which is based on the age-specific size and performance of the bowlers and batters. The objective was a pitch length which enabled young bowlers to bowl good length deliveries while releasing the ball at a more downward angle, similar to elite bowlers. The steeper release angle has the benefit of reducing the sensitivity of the ball flight distance to the variability of ball release. Based on data from county standard under-10 and under-11 players a pitch length of 16.22 yards $(14.83 \mathrm{~m})$ was calculated, $19 \%$ shorter than previously recommended for under-11s in England. A shorter pitch also increases the temporal challenge for batters, encouraging a wider variety of shots and improved anticipation skills. Pitch lengths scaled in this way to fit the players' abilities as they develop will enable a more consistent ball release by bowlers and more consistent temporal demand for batters.
\end{abstract}

Keywords: pitch length; modified sport; bowling; release angle; batting

\section{INTRODUCTION}

While many sports reduce the dimensions of the playing area for junior age groups (for example tennis, soccer, baseball, field hockey), Reid, Buszard, \& Farrow (2018) commented that most youth sport modification guidelines "come without any supporting empirical evidence" and "are a blend of educated guesses and practical design thinking." (p. 1285). This practical design approach often (understandably) adapts junior pitches or courts to coincide with existing markings, for example juniors playing across the width of a full-sized tennis court or hockey or soccer pitch. Reid et al. (2018) called on sport science and medicine professionals to direct more of their efforts to the subject of modified sports for juniors.

Prior to 2019 the England and Wales Cricket Board (ECB) pitch length recommendations for junior cricket were disproportionately long. In the simplest terms, the 20-yard $(18.29 \mathrm{~m})$ long under-11 pitch was 12.75 times the height of the average 11-year-old. This is equivalent to requiring adults to play on a 24.7-yard $(22.6 \mathrm{~m})$ pitch, $12 \%$ longer than the standard 22 yards $(20.12 \mathrm{~m})$.

There is increasing evidence in support of scaling the playing environment, and equipment, to enhance junior sport and produce something more closely comparable to the adult version (Burton, Gillham, \& Hammermeister, 2011; Buszard, Reid, Masters, \& Farrow, 2016). However, the method of scaling the playing environment has received little attention. Scaling on basis of relative height is superficially appealing, but the question of who should form the reference group remains. Elite adults in many sports tend to be taller than average and in the 20th Century the difference from the general population increased (Norton \& Olds, 2001), while the playing area dimensions were specified many years ago when people were shorter (Cole, 2003).

In many sports some account of the physical capabilities of the players, rather than just their size, would seem appropriate. For example, Chase, Ewing, Lirgg, \& 
George (1994) studied basketball shooting by 9- to 12-year-olds and found height not to be strongly related to shooting performance, but speculated that strength may be important, particularly for girls. Timmerman et al. (2015) used the time between successive groundstrokes in junior and elite adult tennis to derive a scale factor for court size and net height, thereby incorporating more than simply the stature of the players.

In junior cricket, Harwood, Yeadon, \& King (2018a) showed that playing measures (such as the number of playable deliveries and amount of running between the wickets) and player involvement improved when under-10s and under-11s played on a 16-yard pitch (as recommended by a high-level coach) compared with 19- or 20 yard pitches. Shortening the pitch encouraged top bowlers in those age groups to release the ball with a more downward trajectory (Harwood, Yeadon, \& King, 2018b); on average they bowled standard deliveries at $4.2^{\circ}$ below horizontal on 16 yards $(14.63 \mathrm{~m})$ compared to $0.7^{\circ}$ below on 19 yards $(17.37 \mathrm{~m})$, much closer to the $7^{\circ}$ below horizontal found for elite pace bowlers (Cork, Justham, \& West, 2012; Justham, West, \& Cork, 2008; Worthington, 2010). Bowling on pitches which are disproportionately long, requires young players to change the way they release the ball as they "grow into" the pitch length, something also noted by Whiteside, Elliott, Lay, \& Reid (2013) in relation to tennis serving. Of more concern, it has also been suggested that playing on disproportionately long pitches could put players at increased risk of injury (Elliott, Plunkett, \& Alderson, 2005). Furthermore, Portus and Farrow (2011) suggested that junior pitch lengths should be modified to increase the temporal demands on batters and encourage the development of anticipatory skills, and Harwood, Yeadon and King (2019) found that a shorter pitch improved the coupling between delivery length and shot selection.

In the light of the evidence from other sports and cricket research suggesting benefits of playing on a shorter pitch, this study aimed to develop a method to scale the cricket pitch length and to calculate the best pitch length for a specific age group. The starting proposition was that the pitch length for a given age group should enable good bowlers to bowl a "good length" delivery when bowling at a realistic speed and from a realistic release position, while releasing the ball with an initial trajectory close to that of top adult bowlers. The long-standing definition of a "good length" is the region where batters are least certain whether to play a front or back foot shot was used (Bradman, 1958). These factors were incorporated into a model which was used to calculate a new pitch length for age group players and also to evaluate the influence of model parameters on the ball flight distance.

\section{METHODS}

The approach taken modelled the pitch as three contiguous length components, which were then estimated using data available for under-11 male cricketers in published research and combined to determine a proposed new pitch length. The assumptions and sensitivity of the model, and implications for players were then explored. Ethical approval for this study was given by the university ethics committee, and the published research from which data were obtained had also received ethical approval as well as obtaining parental consent and player assent.

\section{The Model}

The length of the pitch was divided into three horizontal components: Release Distance, Flight Distance and the Good Length Distance (Figure 1): 


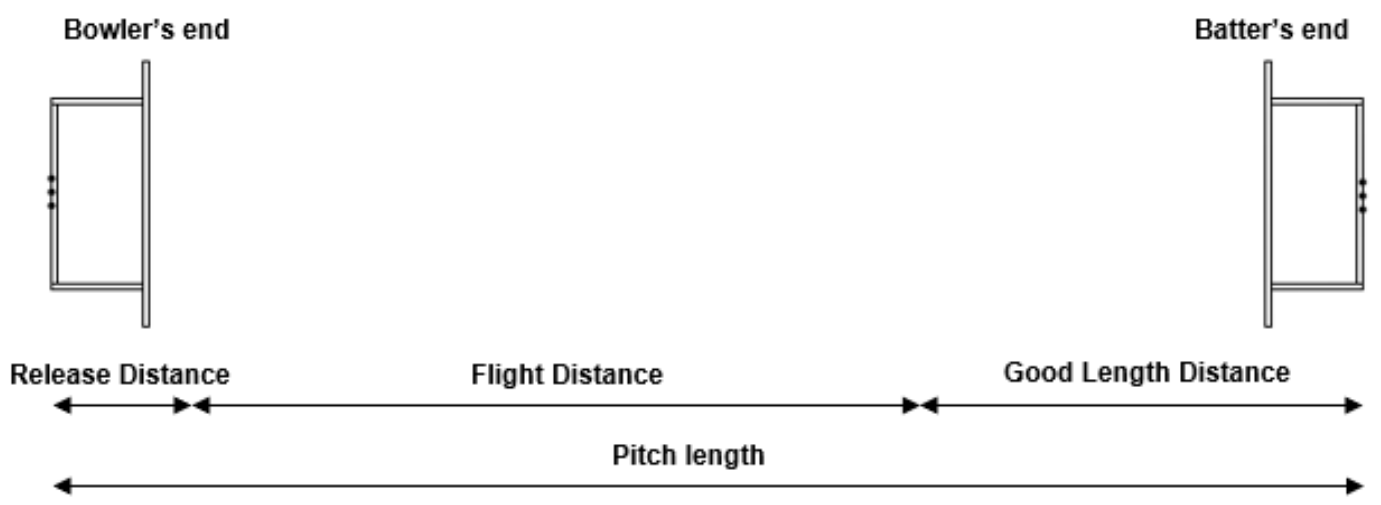

Figure 1. The three components of the pitch length.

Note: Release distance: from the bowler's end stumps to the ball position at release; Flight Distance: from the point of release to bounce point, determined by the initial conditions of ball release height, speed and angle; Good Length Distance: from bounce point to batter's end stumps.

Model inputs

Harwood et al. (2018b) gathered ball release data from twenty under-11 male, right-arm county or top club seam bowlers. Each bowled 12 standard deliveries at their usual pace on both a 19-yard $(17.37 \mathrm{~m})$ and a 16-yard $(14.63 \mathrm{~m})$ pitch at an indoor practice facility, using a leather, four-piece, $135 \mathrm{~g}$ junior ball (Table 1). For the purpose of the model, the ball was considered to be released with the heel of the bowler's front foot at the back edge of the bowling crease, $1.22 \mathrm{~m}$ from the stumps, in accordance with the Laws of Cricket (Marylebone Cricket Club, 2017) and ahead of the bowler's heel by $30 \%$ of the average stature of an 11-year-old British male (1.43 m; Royal College of Paediatric and Child Health, 2012). This gave a Release Distance of $0.43 \mathrm{~m}$ in front of the front heel. Similarly, the height of centre of the ball at release was calculated to be $1.59 \mathrm{~m}$ above the ground, $111 \%$ of average 11 -yearold male stature.

Table 1. Bowler and ball release data (summarised from Harwood et al., 2018b)

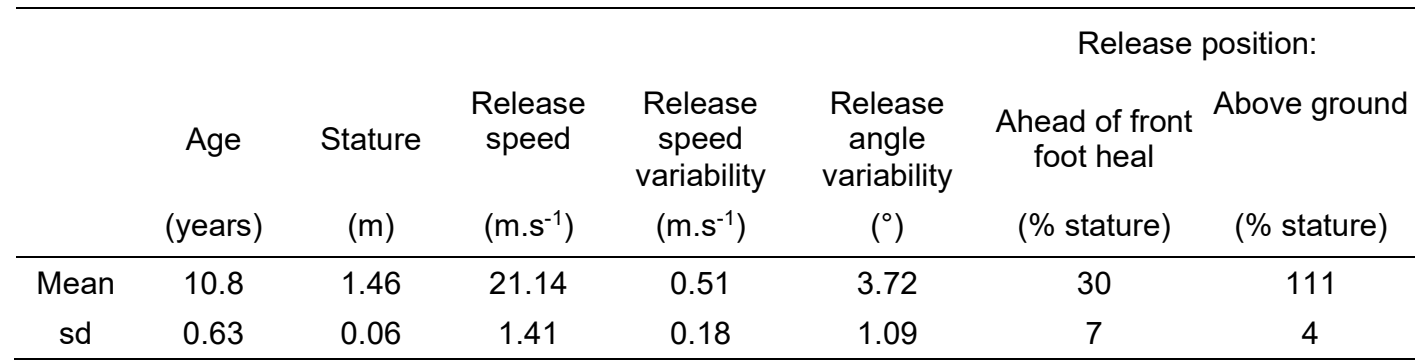

Note: Release speed variability and release angle variability are the means of the individual variabilities of the 20 bowlers.

For standard ("stock") deliveries elite adult pace bowlers have been found to project the ball at around $7^{\circ}$ below horizontal and at speeds around $35 \mathrm{~m} . \mathrm{s}^{-1}$ (e.g. Bartlett, Stockill, Elliott, \& Burnett, 1996; Cork et al., 2012; Justham et al., 2008; King, Worthington, \& Ranson, 2016; Worthington, 2010). However, elite pace bowlers are generally tall: of the 20 emerging male national pace bowlers studied by Worthington (2010), 12 were taller than $90^{\text {th }}$ centile and only three less than $70^{\text {th }}$ centile. To compensate for this skewed distribution, the model was used to estimate the 
projection angle necessary for an average height adult (1.78 m; Moody, 2013) to bowl a good length on a $20.12 \mathrm{~m}$ (22-yard) pitch, releasing the ball at a speed of 35 $\mathrm{m} . \mathrm{s}^{-1}$ from a typical release position (using the proportions above). Measured from the batters' stumps, the Good Length Distance for this simulation was $6.15 \mathrm{~m}(6.73$ yards), while for junior simulations it was taken to be $5.27 \mathrm{~m}$ (5.76 yards), these distances being the centres of the good length regions estimated by Harwood et al. (2019) based on a literature survey and analysis of 10-year-old top order county batters respectively. The adjusted projection angle was then used when calculating a pitch length for average height juniors.

Model detail, application and evaluation

Simulations were conducted neglecting air resistance (using equations of constant gravitational acceleration) and also including air resistance. In the latter case a drag force, $F_{d}=\frac{1}{2} \rho A C_{d} v^{2}$, acting tangentially to the ball's motion, at velocity $\mathrm{v}$, was included in addition to gravity, and Euler's Method (with a time step of $10^{-4} \mathrm{~s}$ ) was used to arrive at numerical solutions. Air density, $\rho$, was taken to be $1.225 \mathrm{~kg} . \mathrm{m}^{-}$ 3; A, the cross-sectional area of a junior cricket ball is $3.6 \times 10^{-3} \mathrm{~m}^{2}$ and $4.07 \times 10^{-3} \mathrm{~m}^{2}$ for a senior ball; $C_{d}$, the drag coefficient has been found to be approximately 0.5 for a senior cricket ball at speeds between 20 and $34 \mathrm{~m} . \mathrm{s}^{-1}$ and at typical ball seam angles, measured with respect to the air flow, (Sayers \& Hill, 1999). Pitch length calculations were made using the junior and senior input data, both with and without drag, and the percentage differences in the Flight Distance and overall pitch length were calculated.

To quantify the temporal challenge to a batter on a given pitch length, the time from the point of ball release to reaching the batter at the crease was calculated assuming a non-bouncing delivery (full toss) was bowled. Mean $\left(21.14 \mathrm{~m} . \mathrm{s}^{-1}\right)$ and fastest individual median $\left(23.9{\left.\mathrm{~m} . \mathrm{s}^{-1}\right)}^{-}\right.$ball speeds from Harwood et al. (2018b) and a

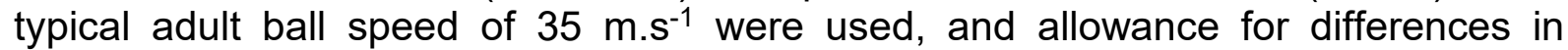
bowler stature and therefore release position was made. Air resistance was neglected in the calculation of these times.

The sensitivity of the pitch length estimate to ball release speed, release angle and release height percentage was evaluated by varying each in turn while fixing the others. Release speed and angle were adjusted by the mean variability (mean of the individual standard deviations) of the junior bowlers, $0.5 \mathrm{~m} . \mathrm{s}^{-1}$ and $3.7^{\circ}$ respectively (Harwood et al., 2018b), but intra-individual variability in release height percentage was negligible, therefore this was varied by the inter-bowler variability of $4 \%$ (equivalent to $0.057 \mathrm{~m}$ for an average height 11-year-old boy).

The range of ball release speeds and projection angles that could be bowled while still bouncing the ball within the good length region on both a 19-yard $(17.37 \mathrm{~m})$ pitch and the newly calculated pitch length were determined. Release height and distance from the front heel were fixed at $111 \%$ and $30 \%$ of mean stature for an 11 year-old male respectively as before. Projecting the ball at an angle that would hit the centre of the good length region (5.76 $\mathrm{yd} / 5.27 \mathrm{~m}$ from the batters' stumps) for balls bowled at $21.14 \mathrm{~m} . \mathrm{s}^{-1}$ on each pitch length, the release speeds which would land the ball 0.75 yards shorter and fuller (the limits of the good length region defined by Harwood et al., 2019) were found. In a similar way, with a fixed ball speed of 21.14 $\mathrm{m} . \mathrm{s}^{-1}$ the ball projection angles necessary to hit the limits of the good length region were calculated. 
The relationships between Flight Distance and both release speed and projection angle were explored by plotting Flight Distance against each parameter in turn over a range of reasonable values for the age group (speeds between 18 and 25 $\mathrm{m} . \mathrm{s}^{-1}$ and angles from $+3^{\circ}$ to $-10^{\circ}$ as reported by Harwood et al. (2018b). Least squares fits to the data then enabled the gradients of the curves to be found at selected release speeds and angles.

\section{RESULTS}

The ball projection angle necessary for an average height adult to bowl a good length on a $20.12 \mathrm{~m}$ pitch was calculated to be $-6.2^{\circ}$ (i.e. below horizontal) when air resistance was neglected and $-6.0^{\circ}$ when it was included. Flight Distance estimates for the average junior's deliveries varied by less than $1.4 \%$ with and without air resistance at these angles. With a ball projection angle of $-6.2^{\circ}$ the pitch length calculated was $14.83 \mathrm{~m}$ (16.22 yards) neglecting air resistance and $14.72 \mathrm{~m}$ (16.10 yards) including air resistance, less than $1 \%$ difference.

The time from ball release to reaching the batting crease, often called "transit time" (e.g. Justham, West, Harland, \& Cork, 2006; Penrose \& Roach, 1995) for full tosses bowled at typical under-11 bowling speeds are much closer to the equivalent time for an adult bowling on a full length pitch on the newly calculated pitch length than the 20-yard recommendation (Table 2).

Table 2. Time from ball release to the batting crease for full tosses bowled on different pitch lengths and at different speeds

\begin{tabular}{lcccc}
\hline Bowler & $\begin{array}{c}\text { Pitch } \\
\text { length } \\
(\mathrm{yd} / \mathrm{m})\end{array}$ & $\begin{array}{c}\text { Ball } \\
\text { speed } \\
\left(\mathrm{m}^{-1} \mathrm{~s}^{-1}\right.\end{array}$ & $\begin{array}{c}\text { Transit } \\
\text { time } \\
(\mathrm{ms})\end{array}$ & $\begin{array}{c}\text { Time difference } \\
(\%)\end{array}$ \\
\hline Adult & $22 / 20.12$ & 35 & 490 & - \\
Under-11 & $20 / 18.29$ & 21.14 & 729 & +49 \\
Under-11 & $20 / 18.29$ & 23.9 & 645 & +32 \\
Under-11 & $16.22 / 14.83$ & 21.14 & 566 & +16 \\
Under-11 & $16.22 / 14.83$ & 23.9 & 500 & +2 \\
\hline
\end{tabular}

Note: 20 yards is the pre-2019 ECB recommended under-11 pitch length; 16.22 yards is the model derived pitch length; $21.14 \mathrm{~m} . \mathrm{s}^{-1}$ is an average under-11 bowling speed and $23.9 \mathrm{~m} . \mathrm{s}^{-1}$ is representative of the fastest individual, both reported in Harwood et al. (2018b).

The pitch length estimate was found to be sensitive to the typical variability in the projection angle displayed by young players, but insensitive to their variability in release speed and release height as a percentage of stature (Table 3).

Table 3. Sensitivity of pitch length to input parameter perturbation

\begin{tabular}{|c|c|c|c|c|c|}
\hline $\begin{array}{c}\text { Ball } \\
\text { speed } \\
\left(\mathrm{m} \cdot \mathrm{s}^{-1}\right)\end{array}$ & $\begin{array}{c}\text { Release } \\
\text { height } \\
(\%)\end{array}$ & $\begin{array}{c}\text { Projection } \\
\text { angle } \\
\left({ }^{\circ}\right)\end{array}$ & $\begin{array}{c}\text { Flight } \\
\text { Distance } \\
(\mathrm{m})\end{array}$ & $\begin{array}{l}\text { Pitch length } \\
\qquad(\mathrm{m})\end{array}$ & $\begin{array}{c}\text { Pitch length } \\
\text { difference } \\
(\%)\end{array}$ \\
\hline 21.14 & 111 & -6.2 & 7.91 & 14.83 & - \\
\hline 20.64 & 111 & -6.2 & 7.79 & 14.71 & -0.8 \\
\hline 21.64 & 111 & -6.2 & 8.02 & 14.94 & +0.8 \\
\hline 21.14 & 107 & -6.2 & 7.70 & 14.62 & -1.4 \\
\hline 21.14 & 115 & -6.2 & 8.11 & 15.03 & +1.3 \\
\hline 21.14 & 111 & -2.5 & 10.06 & 16.98 & +14.6 \\
\hline 21.14 & 111 & -9.9 & 6.32 & 13.23 & -10.7 \\
\hline
\end{tabular}


Note: Emboldened figures represent the typical variability in each input parameter from Harwood et al. (2018b). For ball speed and projection angle these are the top line figures \pm the means of the variabilities of 20 bowlers; for release height it is the base figure $\pm 0.057 \mathrm{~m}$, the inter-bowler variability of $4 \%$ of stature calculated for an 11year-old boy of average stature.

For 19-yard and 16.2-yard pitch lengths the ranges of ball release speeds which would still result in balls bouncing within the good length region were $3.18 \mathrm{~m} . \mathrm{s}^{-1}$ and $5.97 \mathrm{~m} . \mathrm{s}^{-1}$ respectively and the projection angle ranges were $2.0^{\circ}$ and $2.8^{\circ}$. Thus, on the shorter pitch there is an $88 \%$ greater tolerance in speed and $40 \%$ greater tolerance in angle.

Across the typical young bowlers' range of ball release speeds and projection angles, release speed is approximately linearly related to Flight Distance and has a limited influence on it. The gradient of the line is $0.23 \mathrm{~s}$ (metres per [metres per second]) for projection at an angle of $-6.2^{\circ}$ compared with $0.51 \mathrm{~s}$ at an angle of $-0.7^{\circ}$, the mean angle found for this age group when bowling on a 19-yard pitch (Figure 2).

Flight Distance has an approximately quadratic relationship with projection angle over a typical range (Figure 3). Regardless of release speed, the gradient of the curve is shallower as the ball is projected more steeply downwards. For example, releasing at $21.14 \mathrm{~m} . \mathrm{s}^{-1}$ the gradient at $-6.2^{\circ}$ is 0.51 metres per degree, while at $-0.7^{\circ}$ it is 0.76 metres per degree.

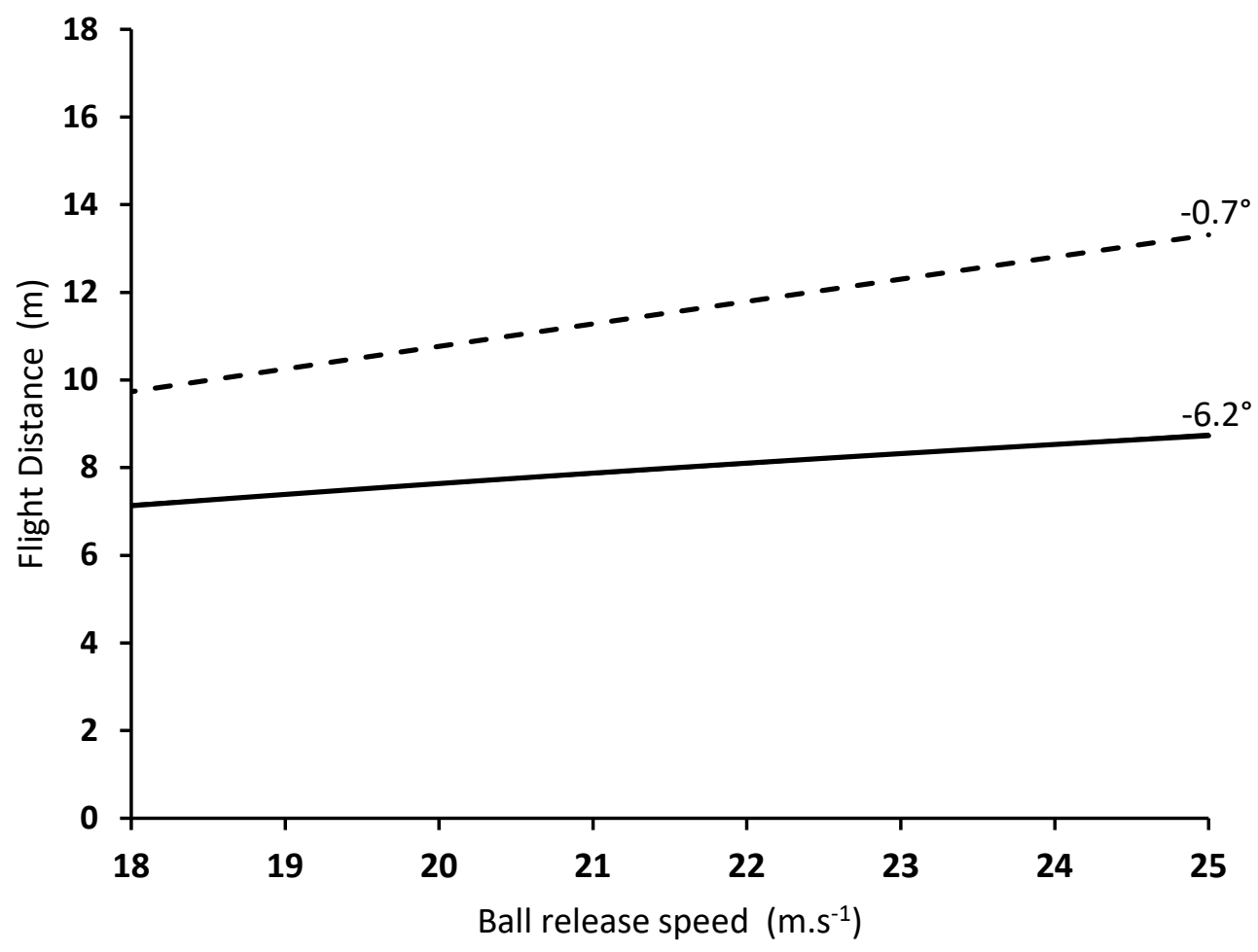

Figure 2. Flight Distance over a typical range of ball release speeds when projection is at $-0.7^{\circ}$ and $-6.2^{\circ}$ and release height is $1.553 \mathrm{~m}(111 \%$ of average height minus ball radius $)$. 


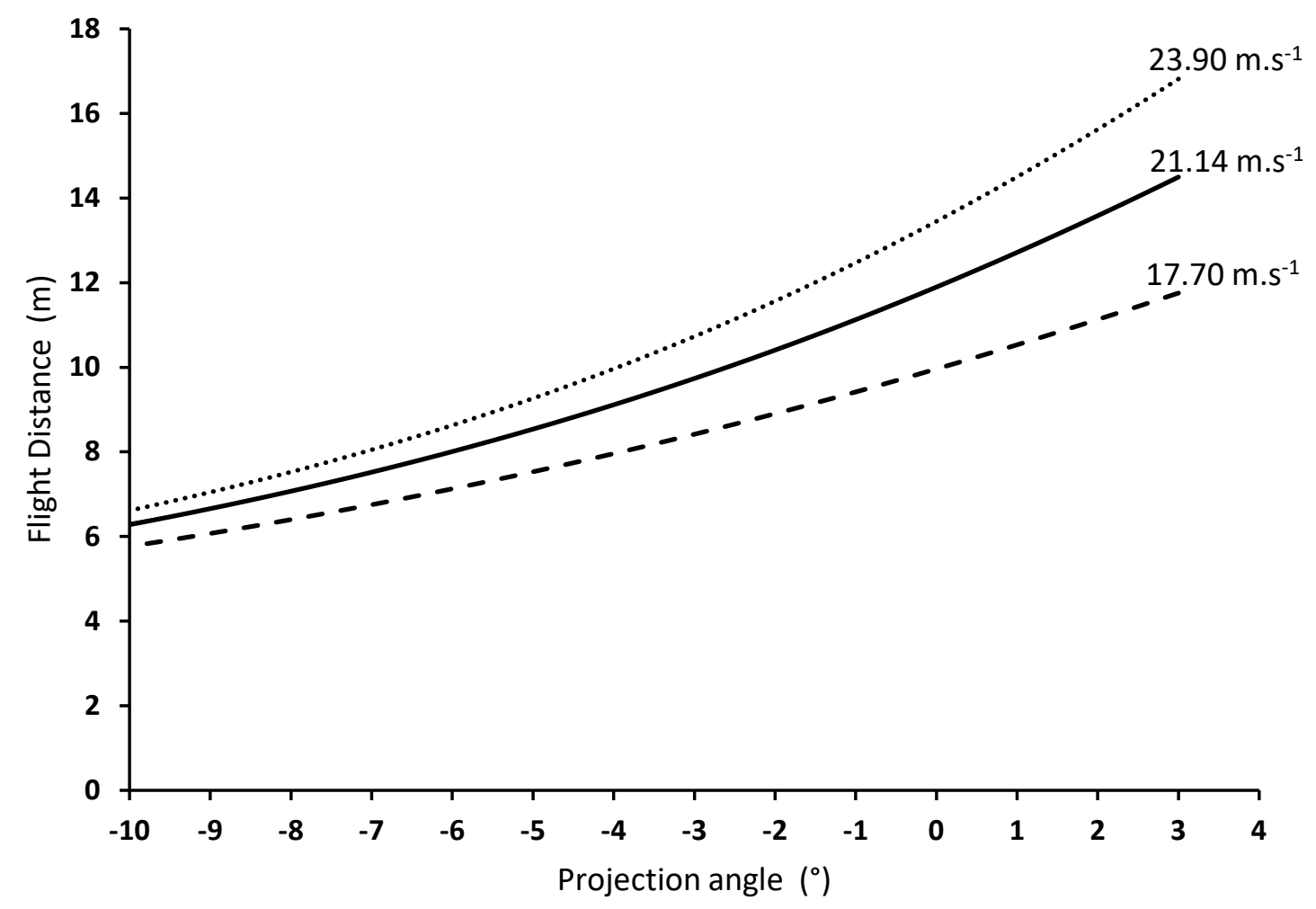

Figure 3. Flight Distance over a typical range of ball projection angles at three release speeds (slowest, fastest

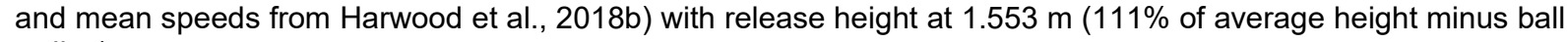
radius).

\section{DISCUSSION}

The cricket pitch length was modelled to enable the calculation of an optimal length based on realistic characteristics of both the bowlers and batters within an age group. Inputs were the typical bowling speed and ball release position of the bowlers, and the distance from the batting end stumps that the ball should bounce in order to produce the greatest indecision for batters when choosing whether to play a front or back foot shot. The flight of the ball from release to bounce was modelled with and without air resistance, using projection angles of $-6.0^{\circ}$ and $-6.2^{\circ}$ respectively, which were calculated to be representative of an elite-pace bowler of average adult height bowling a good length delivery.

The influence of air resistance was found to be negligible; drag impedes the ball's horizontal motion, but for balls projected below horizontal drag also increases the time before bounce occurs. Overall, including drag in the simulations showed it to reduce Flight Distance by less than $2 \%$ even at adult bowling speeds with a senior sized ball and the resulting pitch lengths for under-11s differed by less than $1 \%$. The coefficient of drag used, 0.5 , is typical for senior-sized cricket balls moving at less than the critical Reynolds number of approximately $1.5 \times 105$ (Mehta and Wood,

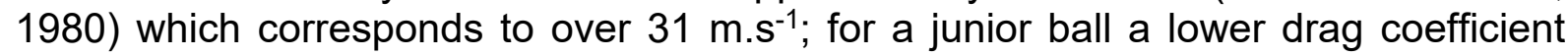
could be justified. Although the Magnus force created by the backspin imparted to the ball was not incorporated, it has been shown to have a smaller influence than drag in cricket bowling (Sayers and Hill, 1999) and any influence it does have keeps the ball in the air for longer, further counteracting the potential Flight Distance reduction by the horizontal drag component. At high bowling speeds and backspin rates it has been suggested that it could actually increase the length of ball flight (Robinson and Robinson, 2015). Therefore, it is reasonable to conclude that aerodynamic factors 
can be ignored when estimating the Flight Distance of the ball at the speeds and over the distances typical in cricket bowling.

The model calculated pitch length of 16.22 yards $(14.83 \mathrm{~m})$ is $19 \%$ shorter than the pre-2019 recommendation of 20 yards $(18.29 \mathrm{~m})$ for under-11s. Scaling a full length pitch simply based on the ratio of the average height of an 11-year-old to that of an adult would give a 17.84-yard $(16.31 \mathrm{~m})$ pitch, still $10 \%$ longer than our new estimate, emphasising the influence of incorporating performance information in the scaling method. The performance data were based on a high standard of age group players thereby ensuring that the pitch length would still require bowlers to bowl well. The new length is close to the 16 yards recommended by an experienced ECB Level 4 coach based on pilot game observations (Harwood et al., 2018a), but somewhat shorter than Cricket Australia's recently adopted recommendation of $16 \mathrm{~m}$ (17.5 yards) for under-11s (Cricket Australia, 2017).

The temporal challenge for batters was estimated by simulating full toss (nonbouncing) deliveries and calculating the transit time from release to batting crease. The 490 ms transit time estimated for adults is reasonable when compared with the 530 to 560 ms suggested by Justham et al. (2006) and Sarpeshkar, Mann, Spratford, and Abernethy (2017) for deliveries bouncing before reaching the batter. On a 20yard pitch under-11 batters have $30 \%$ to $50 \%$ more time than adults in which to select and play their shot, even if the ball doesn't bounce. On the 16.22-yard (14.83 $\mathrm{m})$ pitch calculated using the model, the transit time was reduced to $566 \mathrm{~ms}$ for an average speed delivery, $16 \%$ longer than the adult figure, and $500 \mathrm{~ms}$ (still $2 \%$ longer than adults) for the fastest under-11 bowler's median speed. Even though the ball will arrive at the batter sooner on a shorter pitch, the bowlers are not bowling faster, so the time during which the ball is in the striking zone is unchanged.

Studies have shown that coincidence timing accuracy, typically measured when participants attempt to intercept a moving target, as in catching or striking a moving object, improves mainly up to the age of 10 or 11 (e.g. Benguigui and Ripoll, 1998; Kim, Nauhaus, Glazek, Young, and Lin, 2013). This suggests that 11-year-old batters should be capable of managing the shorter time available; in fact it should improve upon the previous situation where the limited temporal demand on junior batters was unlikely to encourage them to develop the anticipation skills characteristic of experts (Farrow and Reid, 2012; Müller and Abernethy, 2012; Weissensteiner, Abernethy, Farrow, and Müller, 2008). It should lead implicitly to batters attending more to bowlers' movements and the associated outcomes of those movements, and to them exploring a more varied range of shots in response. Reassurance that young batters are able to manage a greater temporal demand is evident from Harwood et al. (2018a) where it was found that on 16-yard $(14.63 \mathrm{~m})$ pitches, county under-10 and club under-11 batters played a wider variety of shots and ran more.

Dupuy, Motte, and Ripoll (2000) illustrated that, in the absence of aerodynamic factors, projectile range sensitivity to speed and projection angle varied substantially depending upon the projection angle itself. The range-projection angle curve has a fairly broad, flat peak for projection angles in the $30^{\circ}$ to $60^{\circ}$ region typical of shot put, basketball free throws, kicking for distance and petanque (boules) for example (Dupuy et al., 2000; Hamilton and Reinschmidt, 1997; Linthorne, 2001; Linthorne and Patel, 2011). However, for projection at or just below horizontal, as in cricket bowling and tennis serving, the curve is relatively steep, but becomes gradually flatter (less sensitive) as the projection angle becomes more downward (Figure 3). The sensitivity of Flight Distance to projection angle variability is reduced by approximately a third between $-0.7^{\circ}$ (the average projection angle for top under -11 
bowlers on a 19-yard pitch) and $-6.2^{\circ}$ suggested here. What is more, a delivery bouncing in the good length region can be achieved with a $40 \%$ greater range of angles on the shorter pitch (a "projection angle window" of $2.8^{\circ}$ compared with $2.0^{\circ}$ ). Therefore, a shorter pitch means a larger margin of error in projection angle when attempting to hit the same pitch region, meaning that bowling outcomes are likely to be more consistent even if the individual bowler is just as variable in ball projection angle. Batters also benefit because inconsistencies in release angle affect the bounce location less, helping shot selection.

Being able to bowl the ball into the good length region more successfully should mean that bowlers can bowl with more freedom and fluidity, akin to the increase in attacking play found in tennis when the net height is reduced (Limpens, Buszard, Shoemaker, Savelsbergh and Reid, 2018). Increasing success also lends itself to implicit learning of the bowling technique and variations, as well as leading to more engagement and self-efficacy (Buszard, Farrow and Reid, 2020; Chase et al, 1994; Farrow and Reid, 2010).

Release height and distance are related to stature and technique, but their influence on pitch length is small, so while the pitch length in this study was based on the average height of an 11-year-old, it would still be appropriate for taller and shorter players in or close to the age group. Furthermore, even release speed has a limited influence on predicted pitch length at projection angles below horizontal, with the gradient of the Flight Distance-release speed curve being lower for ball projection angles further below horizontal (Figure 2).

Given the importance of the projection angle it seems sensible to limit the need for bowlers to adjust it as they mature, that is to say, scale the pitch appropriately with projection angle as a determinant of the length. By incorporating realistic ball release parameters in the pitch scaling method, bowlers should be able to keep the fundamentals of their technique the same as they develop physically and focus more on subtler aspects of pace bowling such as generating swing and movement off the pitch.

Using release height and distance as a proportion of stature indicates but does not completely specify technique. Further research should address in more detail the influence of pitch length on bowling technique, both in comparison with recommended technique and with respect to the propensity for injury on pitches shorter than those recommended by Elliott et al. (2005).

This research used published data from seam bowlers, not least because genuine spin bowlers are in a very small minority at younger age groups. On the longer pitches previously used, young bowlers have tended to bowl the ball with a higher trajectory than adults, in order to reach the batter (Harwood et al, 2018b). Anecdotal evidence from coaches has however suggested that on shorter pitches young spin bowlers spin the ball more and bowl with more pace. Therefore, analysis of spin bowlers bowling on the new pitch length should be the subject of future research in order to determine whether this improvement is verifiable.

Unlike some sports where there are constraints such as walls or fences, or where multiple line markings can cause confusion, in cricket adapting the pitch is straightforward, relying only on painting lines on the turf and positioning the stumps. The grass grows quickly and is mown frequently, removing the lines, allowing the same part of the ground to be re-marked at a different length and used for another age group. On non-turf pitches crease lines can be marked and re-marked with tape or chalk, and solid-base stumps used. There is little reason therefore not to make the pitches fit the players better and, based on the research presented here, the ECB 
introduced shorter pitch length recommendations for junior cricket as part of their new junior formats for 2019 (England and Wales Cricket Board, 2018).

\section{CONCLUSIONS}

Scaling the pitch length using the method presented here enables bowlers to release the ball more like elite adult bowlers and if adopted throughout the junior age groups it will remove the need for bowlers to change their ball release point as they develop. Projecting the ball at a more downward angle also reduces the inaccuracy in length that variability in ball projection angle produces, potentially improving implicit learning, self-efficacy and engagement. For batters, the scaled pitch length should afford them the opportunity to learn and play a greater variety of shots, while the reduced time available to them will encourage greater attention to the bowlers and help them to develop the anticipation skills characteristic of skilled adult batters. ECB recommendations now state that junior cricket should be played on shorter pitches determined using the approach presented here (England and Wales Cricket Board, 2018).

\section{DISCLOSURE STATEMENT}

The authors report no conflict of interest.

\section{REFERENCES}

Bartlett, R.M., Stockill, N.P., Elliott, B.C., Burnett, A.F. 1996. The biomechanics of fast bowling in men's cricket: A review. Journal of Sports Sciences, 14, 403-424. https://doi.org/10.1080/026404196367705.

Benguigui, N., Ripoll, H. 1998. Effects of tennis practice on the coincidence timing accuracy of adults and children. Research Quarterly for Exercise and Sport, 69, 217-223. https://doi.org/10.1080/02701367.1998.10607688.

Bradman, D. 1958. The Art of Cricket. London: Hodder \& Stoughton.

Burton, D., Gillham, A. D., Hammermeister, J. 2011. Competitive engineering: Structural climate modifications to enhance youth athletes' competitive experience. International Journal of Sports Science \& Coaching, 6, 201-218. https://doi.org/10.1260/1747-9541.6.2.201.

Buszard, T., Farrow, D., Reid, M. 2020. Designing Junior Sport to Maximize Potential: The Knowns, Unknowns, and Paradoxes of Scaling Sport. Frontiers in Psychology, 10. https://doi.org/10.3389/fpsyg.2019.02878.

Buszard, T., Reid, M., Masters, R.S.W., Farrow, D. 2016. Scaling the equipment and play area in children's sport to improve motor skill acquisition: A systematic review. Sports Medicine, 46(6), 829-843. https://doi.org/10.1007/s40279-015-0452-2.

Chase, M.A., Ewing, M.E., Lirgg, C.D., George, T.R. 1994. The effects of equipment modification on children's self-efficacy and basketball shooting performance. Research Quarterly for Exercise and Sport, 65, 159-168. https://doi.org/10.1080/02701367.1994.10607611.

Cole, T.J. 2003. The secular trend in human physical growth: A biological view. Economics and Human Biology, 1, 161-168. https://doi.org/10.1016/S1570677X(02)00033-3.

Cork, A., Justham, L., West, A.A. 2012. Three-dimensional vision analysis to measure the release characteristics of elite bowlers in cricket. Proceedings of the 
Institution of Mechanical Engineers, Part P: Journal of Sports Engineering and Technology, 227, 116-127. https://doi.org/10.1177/1754337112447264.

Cricket Australia. 2017. Junior playing formats. Retrieved August 1, 2017, from http://community.cricket.com.au/clubs/junior-formats/format-summary.

Dupuy, M.A., Motte, D., Ripoll, H. 2000. The regulation of release parameters in underarm precision throwing. Journal of Sports Sciences, 18, 375-382. https://doi.org/10.1080/02640410050074304.

Elliott, B.C., Plunkett, D., Alderson, J.A. 2005. The effect of altered pitch length on performance and technique in junior fast bowlers. Journal of Sports Sciences, 23, 661-667. https://doi.org/10.1080/02640410400022177.

England and Wales Cricket Board. 2018. ECB Recommended Junior Formats. London, England. Retrieved from https://www.ecb.co.uk/play/junior/juniorformats/junior-pathway.

Farrow, D., Reid, M. 2010. The effect of equipment scaling on the skill acquisition of beginning tennis players. Journal of Sports Sciences, 28, 723-732. https://doi.org/10.1080/02640411003770238.

Farrow, D., Reid, M. 2012. The contribution of situational probability information to anticipatory skill. Journal of Science and Medicine in Sport, 15, 368-373. https://doi.org/10.1016/j.jsams.2011.12.007.

Hamilton, G.R., \& Reinschmidt, C. 1997. Optimal trajectory for the basketball free throw. Journal of Sports Sciences, 15, 491-504. https://doi.org/10.1080/026404197367137.

Harwood, M.J., Yeadon, M.R., King, M.A. 2018a. Reducing the pitch length: Effects on junior cricket. International Journal of Sports Science \& Coaching, 13, 10311039. https://doi.org/10.1177/1747954118772482.

Harwood, M.J., Yeadon, M.R., King, M.A. 2018b. Does shortening the pitch make junior cricketers bowl better? Journal of Sports Sciences, 36, 1972-1978. https://doi.org/10.1080/02640414.2018.1428884.

Harwood, M.J., Yeadon, M.R., King, M.A. 2019. A shorter cricket pitch improves decision-making by junior batters. Journal of Sports Sciences, 37, 1934-1941. https://doi.org/10.1080/02640414.2019.1606760.

Justham, L., West, A.A., Cork, A. 2008. Quantification and characterization of cricket bowling technique for the development of the parameters required for a novel training system for cricket. Proceedings of the Institution of Mechanical Engineers, Part P: Journal of Sports Engineering and Technology, 222, 61-76. https://doi.org/10.1243/17543371JSET25.

Justham, L., West, A.A., Harland, A.R., Cork, A. 2006. Quantification of the cricket bowling delivery: A study of elite players to gauge variability and controllability. The Engineering of Sport 6, 1, 205-210. https://doi.org/10.1007/978-0-387-46050537.

Kim, R., Nauhaus, G., Glazek, K., Young, D.E., Lin, S. 2013. Development of coincidence-anticipation timing in a catching task. Perceptual \& Motor Skills, 117, 319-338. https://doi.org/10.2466/10.23.PMS.117x17z9.

King, M.A., Worthington, P.J., Ranson, C.A. 2016. Does maximising ball speed in cricket fast bowling necessitate higher ground reaction forces? Journal of Sports Sciences, 34, 707-712. https://doi.org/10.1080/02640414.2015.1069375.

Limpens, V., Buszard, T., Shoemaker, E., Savelsbergh, G.J.P., Reid, M. 2018. Scaling constraints in junior tennis: The influence of net height on skilled players' 
match-play performance. Research Quarterly for Exercise and Sport, 89, 1-10. https://doi.org/10.1080/02701367.2017.1413230.

Linthorne, N.P. 2001. Optimum release angle in the shot put. Journal of Sports Sciences, 19, 359-372. https://doi.org/10.1080/02640410152006135.

Linthorne, N.P., Patel, D.S. 2011. Optimum projection angle for attaining maximum distance in a soccer punt kick. Journal of Sports Science and Medicine, 10, 203214.

Marylebone Cricket Club. 2017. Laws of Cricket 2017 Code. London: Marylebone Cricket Club.

Mehta, R.D., \& Wood, D. 1980. Aerodynamics of the cricket ball. New Scientist, 87(1213), 442-447.

Moody, A. 2013. Adult anthropometric measures, overweight and obesity. Health Survey for England - 2012, 1, 1-39. Retrieved from https://digital.nhs.uk/catalogue/PUB13218.

Müller, S., Abernethy, B. 2012. Expert anticipatory skill in striking sports: A review and a model. Research Quarterly for Exercise and Sport. https://doi.org/10.5641/027013612800745059.

Norton, K., Olds, T. 2001. Morphological Evolution of Athletes Over the 20th Century. Sports Medicine, 31, 763-783. https://doi.org/10.2165/00007256-20013111000001.

Penrose, J.M.T., Roach, N.K. 1995. Decision making and advanced cue utilisation by cricket batsmen. Journal of Human Movement Studies, 29, 199-218.

Portus, M.R., Farrow, D. 2011. Enhancing cricket batting skill: implications for biomechanics and skill acquisition research and practice. Sports Biomechanics, 10, 294-305. https://doi.org/10.1080/14763141.2011.629674.

Reid, M., Buszard, T., Farrow, D. 2018. Learning, activity... and injury? Caring for young athletes through appropriately designed modified (developmental) sport. British Journal of Sports Medicine, 52, 1285-1286. https://doi.org/10.1136/bjsports-2017-098061.

Robinson, G., Robinson, I. 2015. The effect of spin in swing bowling in cricket: Model trajectories for spin alone. Physica Scripta, 90. https://doi.org/10.1088/00318949/90/2/028004.

Royal College of Paediatric and Child Health. 2012. Boys UK growth chart 2-18 years. Retrieved from https://www.rcpch.ac.uk/resources/uk-world-healthorganisation-growth-charts-2-18-years.

Sarpeshkar, V., Mann, D.L., Spratford, W., Abernethy, B. 2017. The influence of ballswing on the timing and coordination of a natural interceptive task. Human Movement Science, 54, 82-100. https://doi.org/10.1016/j.humov.2017.04.003.

Sayers, A.T., Hill, A. 1999. Aerodynamics of a cricket ball. Journal of Wind Engineering and Industrial Aerodynamics, 79, 169-182. https://doi.org/10.1016/S0167-6105(97)00299-7.

Timmerman, E.A., Water, J. De, Kachel, K., Reid, M., Farrow, D., Savelsbergh, G.J.P. 2015. The effect of equipment scaling on children's sport performance: The case for tennis. Journal of Sports Sciences, 33, 1093-1100. https://doi.org/10.1080/02640414.2014.986498.

Weissensteiner, J.R., Abernethy, B., Farrow, D., Müller, S. 2008. The development of anticipation: A cross-sectional examination of the practice experiences contributing to skill in cricket batting. Journal of Sport \& Exercise Psychology, 30, 663-684. 
Whiteside, D., Elliott, B.C., Lay, B., Reid, M. 2013. A kinematic comparison of successful and unsuccessful tennis serves across the elite development pathway. Human Movement Science, 32, 835. https://doi.org/10.1016/j.humov.2013.06.003.

Worthington, P.J. 2010. A biomechanical analysis of fast bowling in cricket. Loughborough University. Retrieved from https://dspace.lboro.ac.uk/2134/6839. 